\title{
Analysis of DAZL SNP260 and SNP386 in infertile Chinese males using multi-analyte suspension array
}

\author{
YIJIAN ZHU, MINGFU MA, LING WAN, DANYAN ZHANG, LETIAN ZHAO, LI WEI and LIANBING LI \\ Key Laboratory of Birth Defects and Reproductive Health of The National Health and Family Planning Commission \\ (Chongqing Population and Family Planning Science and Technology Research Institute), Chongqing 400020, P.R. China
}

Received September 24, 2013; Accepted February 11, 2014

DOI: $10.3892 / \mathrm{mmr} .2014 .2634$

\begin{abstract}
The aim of the present study was to investigate the association between two single nucleotide polymorphisms (SNPs) and infertility in Chinese males using multi-analyte suspension array (MASA). A total of 196 male patients with azoospermia or severe oligospermia (sperm density $<5 \times 10^{6} / \mathrm{ml}$, non-obstructed) who had a normal karyotype and no azoospermia factor microdeletions were recruited, along with 40 healthy, fertile males as controls. Two SNPs of the deleted in azoospermia-like (DAZL) gene, SNP260 and SNP386, were genotyped by allele-specific primer extension (ASPE) combined with MASA technology. The SNP260A $>$ G and SNP386A $>$ G mutations were found in the males with infertility. The SNP260, but not the SNP386, mutation was detectable in the control group. The mutation rates in the controls and patients were 2.5 and $3.06 \%$ for SNP260, and 0 and $2.04 \%$ for SNP386, respectively. A $\chi^{2}$ analysis did not identify any significant differences in the frequency of either mutation between the fertile and infertile males. In conclusion, the combination of ASPE and MASA methods for SNP genotyping was high-throughput, accurate and cost-efficient. The method was applied to detect SNP polymorphisms in the $D A Z L$ gene; and neither the A260G nor the A386G polymorphism of $D A Z L$ appeared to be involved in male infertility in the Chinese population.
\end{abstract}

Correspondence to: Dr Lianbing Li, Key Laboratory of Birth Defects and Reproductive Health of The National Health and Family Planning Commission (Chongqing Population and Family Planning Science and Technology Research Institute), No. 18 Honghuang Road, Jiangbei, Chongqing 400020, P.R. China

E-mail: lilianbing677@163.com

Abbreviations: MASA, multi-analyte suspension array; SNP, single nucleotide polymorphism; ASPE, allele-specific primer extension; $D A Z L$, deleted in azoospermia-like

Key words: MASA, SNP, ASPE, DAZL

\section{Introduction}

Male infertility is considered to be associated with azoospermia factor $(A Z F)$, one of several genes located in the Yq11 chromosomal region. The most common mutations identified in $A Z F$ are microdeletions in $A Z F c$ (60\%) $(1,2)$. The members of the deleted in azoospermia $(D A Z)$ gene family are the primary regulators of proliferation in early germ cells and are important candidate genes for male infertility in the $A Z F C$ region (3). There are three genes in the $D A Z$ gene family: $D A Z, D A Z L$ and BOULE. The $D A Z$-like $(D A Z L)$ gene is located in the $3 \mathrm{p} 24$ chromosomal region and is an autosomal homolog of $D A Z ; 83 \%$ of the cDNA coding regions in $D A Z$ and $D A Z L$ are similar (4-6).

A previous study suggested that $D A Z L$ is important in the sperm production process (7). However, there are conflicting studies regarding whether DAZL mutations impact male infertility. Following completion of the human genome project, single nucleotide polymorphisms (SNPs) have been intensively investigated. As genetic markers, SNPs have been associated with pharmacogenomics and disease susceptibility. Two studies $(8,9)$ have described $A>G$ transitions at the SNP260 and SNP386 nucleotide positions of DAZL, and SNP386 was found to be associated with susceptibility to spermatogenic failure in the Taiwanese population. However, studies in other countries, including Italy, India and Japan, have indicated that there is not an association between the two SNPs and spermatogenic impairment (10-13). Thus, the role of the SNP260A $>$ G and SNP386A $>$ G transitions in male infertility is controversial (12-16). To the best of our knowledge, there have been no studies regarding DAZL SNPs in the Chinese population.Therefore, in the present study, the distribution of the DAZL A260G and A386G SNPs in Chinese males was investigated.

The methods for SNP genotyping are advancing. The available technology includes: Restriction fragment length polymorphism (RFLP), Taqman, high performance liquid chromatography and single-strand conformation polymorphism analysis (17). The most common methods used currently in China to detect SNPs are RFLP and DNA sequencing; however, these techniques are limited in their applications due to the high costs in time and resources.

In the present study, a high-throughput, low-cost and low-consumption method that combined allele-specific primer extension (ASPE) and multi-analyte suspension array (MASA) 
Table I. Sequences of Capture probes, ZipCodes and cZipCodes (5'>3').

\begin{tabular}{|c|c|c|c|}
\hline SNP & Capture probe & ZipCode & cZipCode \\
\hline SNP260A & CTGGCCTCTCTGGAGATGGT & CTACAAACAAACAAАCATTATCAA & TTGATAATGTTTGTTTGTTTGTAG \\
\hline SNP260G & CTGGCCTCTCTGGAGATGGC & СТTTAАТССТTТАТСАСТTТАТСА & TGATAAAGTGATAAAGGATTAAAGG \\
\hline SNP386A & GCAAAGAAGCTTCTAATCTCTCAGT & TCAACAATCTTTTACAATCAAATC & ATTTGATTGTAAAAGATTGTTGA \\
\hline SNP386G & GCAAAGAAGCTTCTAATCTCTCAGC & TCAATCATTACACTTTTCAACAAT & ATTGTTGAAAAGTGTAATGATTGA \\
\hline
\end{tabular}

SNP, single nucleotide polymorphism.

Table II. Primer sequences (5'>3) and the sizes of the PCR amplification products.

\begin{tabular}{llc}
\hline PCR product & \multicolumn{1}{c}{ Primer sequence } & Product length (bp) \\
\hline SNP260A Forward & CCTGAGCCTGAACTAACTTAGAATG & 225 \\
SNP260A Reverse & AATATAGCCTTGGCTGGTTGC & 198 \\
SNP386 Forward & GGGAGAAATTGTCACATCATCG & \\
SNP386 Reverse & AAAATTACTCACCCTTTGGACAC & \\
\hline
\end{tabular}

PCR, polymerase chain reaction; SNP, single nucleotide polymorphism; bp, base pairs.

technology was applied (18) to characterize the DAZL SNP260 and SNP386 mutations in a Chinese population sample.

\section{Materials and methods}

Ethics statement. This study was approved by: The Ethics Committee of Chongqing Institute of Science and Technology for Population and Family Planning, the Research Ethics Committees of the Key Laboratory of Birth Defects and Reproductive Health, and the Ethics Committee of the Human Sperm Bank of Chongqing (Chongqing, China). All ethics approvals were provided in compliance with the Declaration of Helsinki (World Medical Association, 2000). All participants included in this study provided informed consent.

Patients and sample collection. A total of 196 males with azoospermia (non-obstructed) or severe oligospermia (sperm density $<5 \times 10^{6} / \mathrm{ml}$ ), but with a normal karyotype and no AZF microdeletions, were recruited from the Affiliate Hospital of Sichuan Genitalia Hygiene Research Center (Chengdu, China). Forty samples from fertile controls comprised of healthy volunteers were collected from the Human Sperm Bank of Chongqing. Whole blood $(5 \mathrm{ml})$ was obtained from all patients and control subjects. Peripheral blood lymphocytes were isolated from the whole blood and stored at $-20^{\circ} \mathrm{C}$ until required for analysis.

Coupling of oligonucleotides to microspheres. The sequences of cZipcodes for SNP260 and SNP386 (Table I) were selected online through Luminex Corporation (Austin, TX, USA). The 5' ends of all cZipcodes were C-12-linked and amino-modified. To couple the cZipcodes to carboxylate beads, 2.5 million carboxylate beads, suspended in $25 \mu 10.1 \mathrm{~mol} / 12$-(N-morpholino)ethanesulfonic acid ( $\mathrm{pH} 4.5)$, were mixed with $0.5 \mathrm{nmol}$ amino-modified cZipcodes. Subsequently, $1.25 \mu 110 \mathrm{mg} / \mathrm{ml}$ fresh 1-ethyl-3- (3-dimethylaminopropyl)carbodiimide hydrochloride was added to the microsphere/oligo mixture and incubated in the dark for $30 \mathrm{~min}$ at room temperature, and this step was repeated twice. The microsphere/oligo mixture was mixed occasionally during incubation to ensure that the microspheres remained in suspension. The bead mixture was washed with $0.5 \mathrm{ml} 0.02 \%$ Tween-20 and $0.5 \mathrm{ml} 0.1 \%$ SDS. The beads were finally resuspended in $50 \mu \mathrm{l}$ Tris-EDTA (pH 8.0) at $4^{\circ} \mathrm{C}$ in the dark.

DNA isolation and polymerase chain reaction (PCR). Genomic DNA was extracted from peripheral blood lymphocytes using a DNA isolation kit (Youjing Corp., Seoul, Korea). PCR was performed in a total volume of $25 \mu \mathrm{l}$ containing $150 \mathrm{ng}$ genomic DNA, 10 mM Tris- $\mathrm{HCl}$ (pH 8.3), $50 \mathrm{mM} \mathrm{KCl,} 1.5 \mathrm{mM}$ $\mathrm{MgCl}_{2}, 200 \mu \mathrm{M}$ dNTPs, $5 \mathrm{pmol}$ of each primer (Table II) and 1.5 U DNA polymerase. The PCR cycling conditions were as follows: $94^{\circ} \mathrm{C}$ for $10 \mathrm{~min}$, followed by 35 cycles of $94^{\circ} \mathrm{C}$ for $30 \mathrm{sec}, 62^{\circ} \mathrm{C}$ for $30 \mathrm{sec}$ and $72^{\circ} \mathrm{C}$ for $5 \mathrm{~min}$.

ASPE. To remove unincorporated dNTPs and primers from the PCR reaction, $2 \mathrm{U}$ Shrimp alkaline phosphatase and $1 \mathrm{U}$ Exonuclease I were added to $10 \mu 1$ of the pooled PCR products. The mixture was incubated at $37^{\circ} \mathrm{C}$ for $15 \mathrm{~min}$, and then the enzymes were inactivated by heating at $95^{\circ} \mathrm{C}$ for $20 \mathrm{~min}$.

The ASPE reaction comprised $10 \mu \mathrm{l}$ enzyme-treated PCR products, $40 \mathrm{mM}$ Tris- $\mathrm{HCl}$ (pH 8.4), $100 \mathrm{mM} \mathrm{KCl,} 25 \mathrm{mM}$ $\mathrm{MgCl}_{2}, 0.5 \mathrm{pmol}$ of each SNP oligonucleotide, $100 \mu \mathrm{M}$ of each dNTP (including biotin-labeled dCTP) and 3 U Tsp DNA polymerase in a total volume of $20 \mu 1$. The PCR cycling conditions were as follows: $96^{\circ} \mathrm{C}$ for $2 \mathrm{~min}$, followed by 30 cycles of $94^{\circ} \mathrm{C}$ for $30 \mathrm{sec}, 55^{\circ} \mathrm{C}$ for $1 \mathrm{~min}$ and $72^{\circ} \mathrm{C}$ for 2 min.

Hybridization of ASPE products to the microspheres. A total of 3,000 probe-coupled microspheres of each type were added 


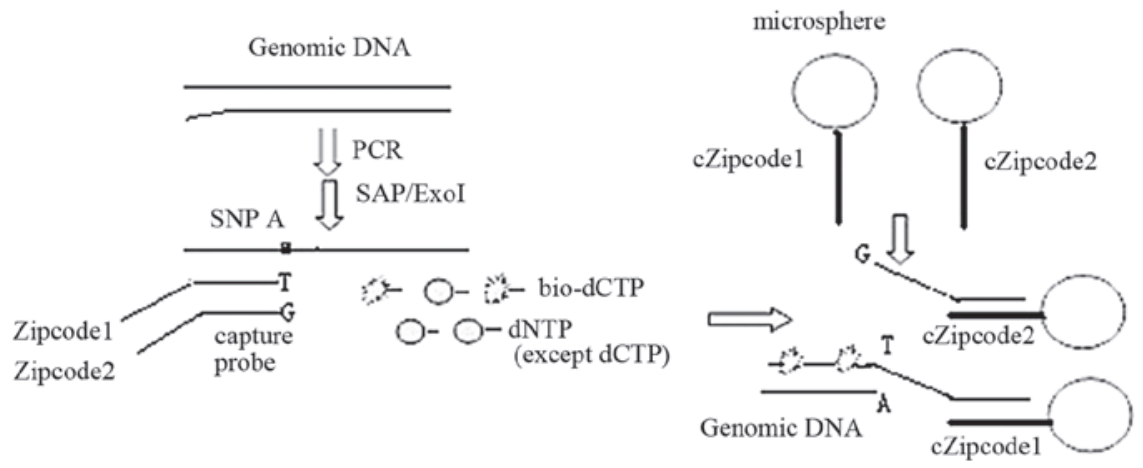

Figure 1. Schematic diagram of the ASPE reaction. In the assay combining ASPE and multi-analyte suspension array, the genomic DNA was amplified by PCR using primers specific for the $\mathrm{A}>\mathrm{G}$ transitions at SNP260 or SNP386. The PCR incorporated a Zipcode tag specific to each allele. The Zipcode tag interacted with cZipcoded microspheres to detect the frequency of each allele. ASPE, allele-specific primer extension; PCR, polymerase chain reaction; SNP, single nucleotide polymorphism; SAP, shrimp alkaline phosphatase; Exonuclease I, ExoI; bio-dCTP, biotin-dCTP.

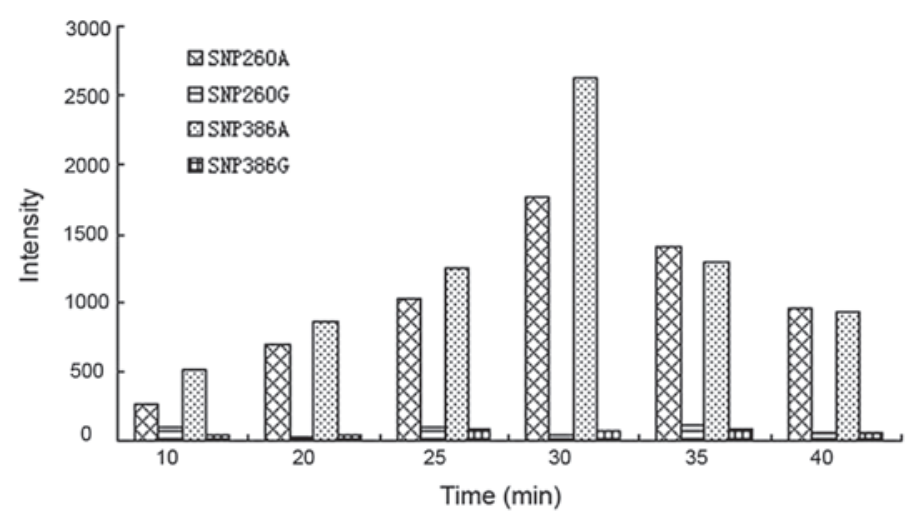

Figure 2. Effect of hybridization time on fluorescence intensity. Zipcode-tagged polymerase chain reaction SNP260 and SNP386 products were incubated with cZipcode-labeled microspheres for 10-40 mins as indicated. The fluorescent signal was then read on a Luminex 100 . The 30 min time point gave the most intense specific fluorescent signal. SNP, single nucleotide polymorphism.

to the ASPE products and $1 \mathrm{X}$ tetramethylammonium chloride was used to obtain a final volume of $50 \mu \mathrm{l}$. The mixture was heated at $90^{\circ} \mathrm{C}$ for $10 \mathrm{~min}$ and then hybridized at $53^{\circ} \mathrm{C}$ for 5 , $10,15,30$ and 45 min to optimize the hybridization time. The hybrid products were labeled with $200 \mathrm{ng}$ fresh streptavidinR-phycoerythrin at $55^{\circ} \mathrm{C}$ for $5 \mathrm{~min}$. The fluorescent signal was measured using the Luminex 100 system (Luminex Corporation).

RFLP and DNA sequencing for verification of the accuracy of the ASPE. All samples identified as SNP mutants using ASPE were sequenced using the alternate methods. Samples randomly selected from the non-mutated infertile males and control patients were also used. The RFLP reaction consisted of $17.3 \mu \mathrm{l}$ purified PCR products, $0.2 \mu \mathrm{l}$ bovine serum albumin, $2 \mu 1$ 10X PCR buffer, and $0.5 \mu 1$ restriction endonuclease DdeI for SNP260 or AluI for SNP386. The total reaction volume was $20 \mu \mathrm{l}$. Following incubation at $37^{\circ} \mathrm{C}$ for $4 \mathrm{~h}$, the enzyme products were analyzed using polyacrylamide gel electrophoresis. PCR products were first cloned (TOPO TA cloning kit; Invitrogen Life Technologies, Carlsbad, CA, USA) according to the instructions of the manufacturer, followed by DNA sequencing. The identification of the obtained sequence was verified by using alignment search tool (BLAST) analysis (www.ncbi.nlm.nih.gov).
Statistical analysis. Statistical analysis was performed using SPSS software, version 13.0 (SPSS, Inc., Chicago, IL, USA). The $\chi^{2}$ test was used to evaluate the genotype distribution and allele frequencies of the polymorphisms. $\mathrm{P}<0.05$ was considered to indicate a statistically significant difference.

\section{Results}

Assay optimization. To assess the association between DAZL mutations and male infertility, the present study aimed to develop a bead-based platform for SNP genotyping of DAZL. A schematic of the ASPE technology applied is shown in Fig. 1. For the SNP genotyping, two capture probes were designed for each SNP site. One primer was complementary to the wild-type sequence and the other was complementary to the mutation. A thermostable polymerase was used to extend the capture probe by incorporation of dNTPs, and one of which was biotin-labeled (Fig. 1). Extension only occurred if the $3^{\prime}$ nucleotide of the probes had annealed to the template DNA. A DNA sequence, termed Zipcode, was added at the 5 '- end portion of the capture probe. The Zipcode hybridized to its complementary sequence, termed cZipcode, which was coupled to a specific fluorescent microsphere (Fig. 1). The sequences of the Zipcode and cZipcode pairs for each SNP are shown in Table I. With the extension of the capture probe, 
Table III. Relative prevalence of mutations in DAZL SNP260 and SNP386 in infertile males and controls.

\begin{tabular}{lcrrr}
\hline & \multicolumn{2}{c}{ Mutation Rate, $\mathrm{n}(\%)$} & & \\
\cline { 2 - 5 } Mutation site & Infertility $(\mathrm{n}=196)$ & Control (n=40) & $\chi^{2}$ & P-value \\
\hline SNP260A $>$ G & $1(2.50)$ & $0(0.00)$ & 0.18 & $>0.05$ \\
SNP386A $>$ G & $6(3.06)$ & $4(2.04)$ & $>0.05$ \\
\hline
\end{tabular}

DAZL, deleted in azoospermia-like; SNP, single nucleotide polymorphism.
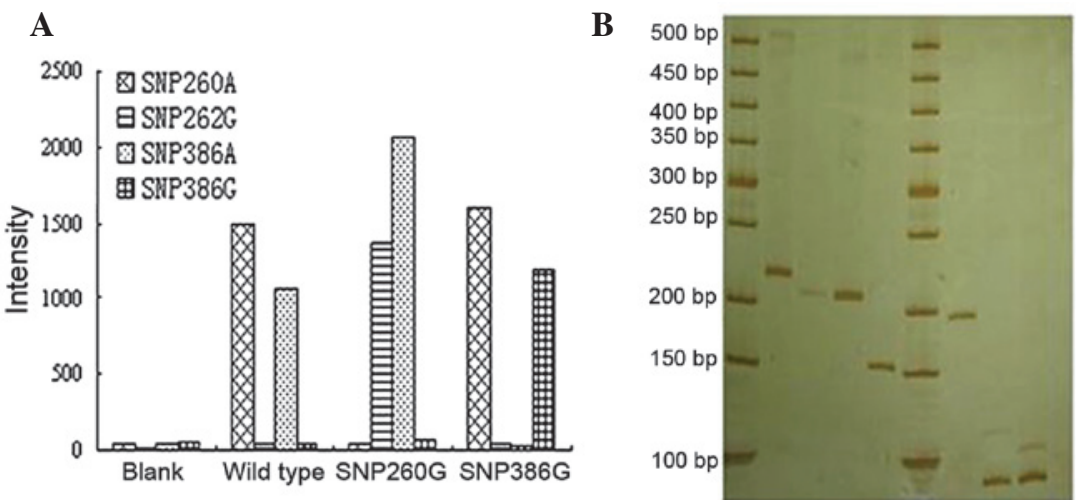

C
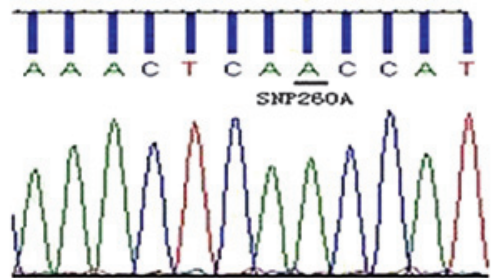

$\mathbf{E}$

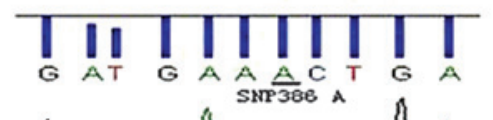

D
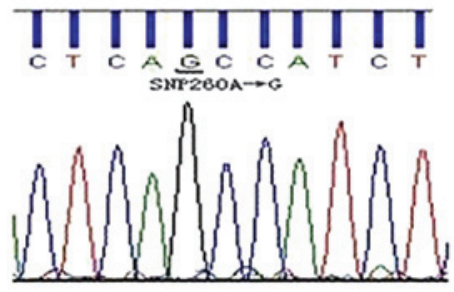

$\mathbf{F}$
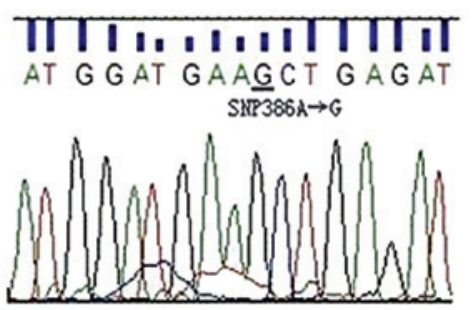

Figure 3. Results of the multi-analyte suspension array, restriction fragment length polymorphism and DNA sequencing. (A) The fluorescence intensity of the blank, wild-type and homozygous mutations of SNP260 and SNP386. (B) Electrophoretic analysis of the PCR products of deleted in azoospermia-like digested by DdeI or AluI; lanes 1 and 6, marker; lane 2, SNP260 PCR products ( $225 \mathrm{bp})$; lanes 3 and 4, SNP260 PCR products with wild-type digested by DdeI (217, 3 and $5 \mathrm{bp}$; the latter two were run off the gel); lane 5, SNP260 PCR products with homozygous mutation digested by DdeI (155, 62, 5 and 3 bp; the latter three were run off the gel); lane 7, SNP386 PCR products (198 bp); lane 8, SNP386 PCR products with wild-type digested by Alu I (118 and 80 bp); lane 9, SNP386 PCR products with homozygote mutation digested by $A l u \mathrm{I}(105,80$ and $13 \mathrm{bp}$, the last was run off the gel). (C) Representative DNA sequence analysis of SNP260 showing the wild-type sequence. (D) Representative SNP260 DNA sequence analysis showing the homozygous mutation. (E) Representative DNA sequence analysis of SNP386 showing the wild-type sequence. (F) Representative SNP386 DNA sequence analysis showing the homozygous mutation. PCR, polymerase chain reaction.

the template DNA was labeled with biotin. Following hybridization and dye incorporation, the signals were captured and analyzed by Luminex 100 .

To optimize the hybridization time, samples of the mixture were incubated for 5, 10, 15, 30 and $45 \mathrm{~min}$. Allowing samples to hybridize for $30 \mathrm{~min}$ achieved the best specificity and highest fluorescence intensity (Fig. 2). For the multiplex bead array screening, a cut-off value was established based on a fluorescence intensity of 100. Results with fluorescence intensity $<100$ were classified as negative. Results classified as positive were at least 10 -fold greater than the negative reading. The results presented had to meet the aforementioned requirements to be considered valid.

SNP260 assayed by ASPE, RFLP and DNA sequencing. In the 196 infertility patients and 40 controls, the heterozygote mutation was not identified using MASA. Only one $(2.50 \%)$ of the 40 controls and six $(3.06 \%)$ of the 196 patients were observed 
to have a homozygous mutation (Table III). The results of the wild-type and homozygous mutations detected by MASA are shown in Fig. 3A. The results obtained using ASPE were consistent with the results obtained using RFLP (Fig. 3B) and DNA sequencing (Fig. 3C-F).

SNP386 assayed by ASPE, RFLP and DNA sequencing. In the enrolled patients, no heterozygote mutations in SNP386 were detected (Table III). Four (2.04\%) of the 196 infertility patients were identified to have the homozygous SNP386 mutation (Table III). All the controls were wild-type homozygous (Table III). However, $\chi^{2}$ analysis did not indicate a statistically significant difference between the groups. The results of the wild-type and homozygous mutations detected by MASA are shown in Fig. 3A. The ASPE results were again consistent with those of the RFLP (Fig. 3B) and DNA sequencing (Fig. 3C-F).

Association between the DAZL mutation and infertility in males. The mutation rates of SNP260 and SNP386 in the controls and patients were low: 0.00 and $2.50 \%$ for SNP260 and 2.04 and $3.06 \%$ for SNP386, respectively. The frequencies of the SNP mutations in the control and infertile males were similar $(\mathrm{P}>0.05)$. This was inconsistent with results reported in a study of controls and infertile male patients from Taiwan (0.86 and $7.39 \%$, respectively, for SNP386) $(8,9)$.

\section{Discussion}

$D A Z L, D A Z$ and BOULE are the three members of the DAZ gene family which encode RNA-binding proteins associated with impaired spermatogenesis. The $D A Z$ gene family contributes to spermatogenesis in a number of different species. Houston et al (19) found that DAZL knockout reduced the number of testicular stem cells in mice and caused spermatogonia to halt in meiosis. They also demonstrated that mice lacking BOULE exhibited impaired spermatogenesis, but the symptoms were corrected by reimplantation of the Xenopus $x D A Z L$ gene. Slee et al (20) have also reported that the human $D A Z L$ gene partially restored function in mice lacking $D A Z L$. Lin et al (21) have shown that males with Sertoli-cell-only syndrome exhibited low levels of expression of DAZL. All these studies demonstrate that the $D A Z L$ gene is important during spermatogenesis.

Spermatogenesis is a complex process regulated by several genes located on autosomal and sex chromosomes (22). Approximately $10 \%$ of infertile males have complete or partial deletions of the $D A Z$ gene cluster $(23,24)$. The hypothesis that $D A Z L$ is involved in spermatogenesis is supported by studies demonstrating its testis-specific expression and its high homology to $D A Z(25,26)$. Studies have indicated that $D A Z L$ may be involved in germ cell development. For example, in Caenorhabditis elegans, inactivation of DAZL was associated with meiotic arrest in oogenesis (27). In mice, knockout of the DAZL homolog led to the loss of germ cells in males and females (28). Additionally, in humans, low mRNA transcript levels of the $D A Z L$ gene were identified in infertile males with testicular failure (29).

However, there have been few studies that establish the association between the human DAZL gene mutation and male infertility. Two studies $(8,9)$ have identified two SNP mutations in DAZL in the Taiwanese population: SNP260A $>\mathrm{G}$ in exon 2 and SNP386A $>$ G in exon 3. SNP386A $>$ G was identified in $7.39 \%$ of infertile males compared with $0.86 \%$ of fertile males. By contrast, studies in India, Japan and Italy observed that SNP386A $>$ G was not associated with male infertility (10-13). Notably, Bartoloni et al (10) found the SNP386 mutation in $<1 / 316$ males with azoospermia and severe oligospermia. It is possible that the mutation may only be associated with infertility in males of Asian descent. However, the present study, conducted using Chinese male participants, also revealed no association between male infertility and the SNP386 mutation. This suggests the SNP386 mutation may be associated with infertility in only the Taiwanese population. Alternatively, the mutation site may be located in non-specific sites of the gene for the RNA-binding protein, and would therefore not likely be important in the sperm production process. To further understand the association between SNP386 and male infertility, additional studies at the protein level are required.

To date, there are four methods compatible with MASA that can be used to genotype SNPs: (i) Single base chain extension (SBCE), (ii) ASPE, (iii) oligonucleotide ligation assay and (iv) direct DNA hybridization (DH) (30). Lee et al (31) compared the accuracy, efficiency and costs of these methods, and showed that SBCE and ASPE are the most accurate. However, SBCE is also the most expensive while DH is the cheapest.

There are numerous advantages of incorporating ASPE and MASA technology to perform targeted high-throughput genetic characterization. ASPE lends itself to this application as it is: Highly specific, cost-efficient, versatile and not labor-intensive. Using ASPE and MASA, the fluorescent signal from the positive results is always $\sim 10$-fold higher than that from the negative results. The high signal-to-noise ratio makes it easy to interpret the results analyzed using a Luminex 100. Furthermore, the experiments can be conducted in $<8 \mathrm{~h}$. The combined technique is also easily scaled and sample throughput may be increased using 96-well plates instead of single tubes (18). It is also possible that by taking advantage of the full bead array, up to 50 SNP sites could be analyzed in a single tube simultaneously. This would minimize consumption of Tsp DNA polymerase and dNTPs, particularly biotin-labeled dCTP. In the full multiplex assay, the more SNP sites genotyped, the less each reaction costs. In traditional MASA formats, the microspheres are directly coupled to specific probes. Thus, each set of beads is only able to genotype one site. However, in assays combining ASPE and MASA, the microspheres are coupled to a non-specific cZipcode. The cZipcode-coupled microspheres can be used to detect almost any SNP linked to a Zipcode tag and specific capture probes.

In the present study, a potential platform was established for SNP research. The results suggested that SNP260 and SNP386 are not linked to azoospermia and severe oligospermia in Chinese males. However, studies are required to understand the important role of $D A Z L$ in spermatogenesis.

The most common methods to detect SNPs currently used in China are based on RFLP or DNA sequencing. However, the current methods are expensive and labor-intensive. In the present study, 196 male patients with azoospermia or severe 
oligospermia (sperm density $<5 \times 10^{6} / \mathrm{ml}$, non-obstructed) that had a normal karyotype and no AZF microdeletions were recruited, along with 40 healthy, fertile controls. SNP260 and SNP386 of DAZL were genotyped using ASPE combined with MASA technology. The combined method for SNP genotyping was high-throughput, accurate and cost-efficient. The technique was successfully applied to detect polymorphisms in the DAZL gene. However, no significant differences were identified between the frequencies of the mutations in SNP260 or SNP386 in the infertile and fertile males $(\mathrm{P}>0.05)$. The A260G and A386G polymorphisms of $D A Z L$ appeared to not affect male fertility in the Chinese population.

\section{Acknowledgements}

The authors thank Chongqing Key Laboratory of Birth Defects and Reproductive Health for funding this study (grant no. 1110). The authors thank Professor XP Ding, Miss. Zhang Min and Miss. Wang Huan for their help with the study.

\section{References}

1. Simoni M, Tüttelmann F, Gromoll J and Nieschlag E: Clinical consequences of microdeletions of the Y chromosome: the extended Münster experience. Reprod Biomed Online 16 289-303, 2008

2. Ferlin A, Arredi B, Speltra E, Cazzadore C, Selice R, Garolla A, Lenzi A and Foresta C: Molecular and clinical characterization of $\mathrm{Y}$ chromosome microdeletions in infertile men: a 10-year experience in Italy. J Clin Endocrinol Metab 92: 762-770, 2007.

3. Giachini C, Nuti F, Marinari E, Forti G and Krausz C: Partial AZFc deletions in infertile men with cryptorchidism. Hum Reprod 22: 2398-2403, 2007.

4. Shan Z, Hirschmann P, Seebacher T, Edelmann A, Jauch A, Morell J, et al: A SPGY copy homologous to the mouse gene Dazla and the Drosophila gene boule is autosomal and expressed only in the human male gonad. Hum Mol Genet 5: 2005-2011, 1996.

5. Seboun E, Barbaux S, Bourgeron T, Nishi S, Agulnik A, Egashira M, et al: Gene sequence, localization and evolutionary conservation of DAZLA, a candidate male sterility gene. Genomics 41: 227-235, 1997.

6. Saxena R, Brown LG, Hawkins T, Alagappan RK, Skaletsky $\mathrm{H}$, Reeve MP, et al: The DAZ gene cluster on the human Y chromosome arose from an autosomal gene that was transposed, repeatedly amplified and pruned. Nat Genet 14: 292-299, 1996.

7. Yen PH: Putative biological functions of the DAZ family. Int J Androl 27: 125-129, 2004.

8. Teng YN,Lin YM,Lin YH, et al: Association of a single-nucleotide polymorphism of the deleted-in-azoospermia-like gene with susceptibility to spermatogenic failure. J Clin Endocrinol Metab 87: 5258-5264, 2002.

9. Teng YN, Chang YP, Tseng JT, et al: A single-nucleotide polymorphism of the DAZL gene promoter confers susceptibility to spermatogenic failure in the Taiwanese Han. Hum Reprod 27: $2857-2865,2012$

10. Bartoloni L, Cazzadore C, Ferlin A, Garolla A and Foresta C: Lack of the T54A polymorphism of the DAZL gene in infertile Italian patients. Mol Hum Reprod 10: 613-615, 2004.
11. Poongothai J, Gopenath TS and Manonayaki S: A386G transition in DAZL gene is not associated with spermatogenic failure in Tamil Nadu, South India. Indian J Hum Genet 14: 16-19, 2008.

12. Becherini L, Guarducci E, Degl'Innocenti S, Rotondi M, Forti G and Krausz C: DAZL polymorphisms and susceptibility to spermatogenic failure: an example of remarkable ethnic differences. Int J Androl 27: 375-381, 2004.

13. Yang XJ, Shinka T, Nozawa S, et al: Survey of the two polymorphisms in DAZL, an autosomal candidate for the azoospermic factor, in Japanese infertile men and implications for male infertility. Mol Hum Reprod 11: 513-515, 2005.

14. Kumar K, Venkatesh S, Sharma PR, Tiwari PK and Dada R: DAZL 260A $>$ G and MTHFR 677C $>$ T variants in sperm DNA of infertile Indian men. Indian J Biochem Biophys 48: 422-426, 2011.

15. Teng YN, Lin YM, Sun HF, Hsu PY, Chung CL and Kuo PL: Association of DAZL haplotypes with spermatogenic failure in infertile men. Fertil Steril 86: 129-135, 2006.

16. Tschanter P, Kostova E, Luetjens CM, Cooper TG, Nieschlag E and Gromoll J: No association of the A260G and A386G DAZL single nucleotide polymorphisms with male infertility in a Caucasian population. Hum Reprod 19: 2771-2776, 2004.

17. Wang WP, Ni KY and Zhou GH: Approaches for SNP genotyping. Yi Chuan 28: 117-126, 2006 (In Chinese).

18. Ye F, Li MS, Taylor JD, et al: Fluorescent microsphere-based readout technology for multiplexed human single nucleotide polymorphism analysis and bacterial identification. Hum Mutat 17: 305-316, 2001

19. Houston DW, Zhang J, Maines JZ, Wasserman SA and King ML: A Xenopus DAZ-like gene encodes an RNA component of germ plasm and is a functional homologue of Drosophila boule. Development 125: 171-180, 1998 .

20. Slee R, Grimes B, Speed RM, et al: A human DAZ transgene confers partial rescue of the mouse Dazl null phenotype. Proc Natl Acad Sci USA 96: 8040-8045, 1999.

21. Lin YM, Chen CW, Sun HS, et al: Expression patterns and transcript concentrations of the autosomal DAZL gene in testes of azoospermic men. Mol Hum Reprod 7: 1015-1022, 2001.

22. Nuti F and Krausz C: Gene polymorphisms/mutations relevant to abnormal spermatogenesis. Reprod Biomed Online 16: 504-513, 2008.

23. Poongothai J, Gopenath TS and Manonayaki S: Genetics of human male infertility. Singapore Med J 50: 336-347, 2009.

24. Reynolds $\mathrm{N}$ and Cooke HJ: Role of the DAZ genes in male fertility. Reprod Biomed Online 10: 72-80, 2005.

25. Jenkins HT, Malkova B and Edwards TA: Kinked $\beta$-strands mediate high-affinity recognition of mRNA targets by the germ-cell regulator DAZL. Proc Natl Acad Sci USA 108: 18266-18271, 2011

26. Kim B, Lee Y, Kim Y, et al: Polymorphic expression of DAZ proteins in the human testis. Hum Reprod 24: 1507-1515, 2009.

27. Karashima T, Sugimoto A and Yamamoto M: Caenorhabditis elegans homologue of the human azoospermia factor DAZ is required for oogenesis but not for spermatogenesis. Development 127: 1069-1079, 2000.

28. Ruggiu M, Speed R, Taggart M, et al: The mouse Dazla gene encodes a cytoplasmic protein essential for gametogenesis. Nature 389: 73-77, 1997.

29. Kuo PL, Wang ST, Lin YM, Lin YH, Teng YN and Hsu CC: Expression profiles of the DAZ gene family in human testis with and without spermatogenic failure. Fertil Steril 81: 1034-1040, 2004.

30. Dunbar SA: Applications of Luminex xMAP technology for rapid, high-throughput multiplexed nucleic acid detection. Clin Chim Acta 363: 71-82, 2006

31. Lee SH, Walker DR, Cregan PB and Boerma HR: Comparison of four flow cytometric SNP detection assays and their use in plant improvement. Theor Appl Genet 110: 167-174, 2004 